\title{
Assessment of Climate Change Impact on Water Availability of Bilate Watershed, Ethiopian Rift Valley Basin
}

\author{
Abadi Tekle \\ Department of Water Resources and Irrigation Engineering, Aksum University, Shire, Ethiopia \\ PO box 314, Shire, Ethiopia \\ E-mail: tekleabadi@yahoo.com \\ Kassa Tadele \\ Department of Water Resources and Irrigation Engineering, Arba Minch University, Arba Minch, Ethiopia \\ PO box 21, Arba Minch, Ethiopia \\ E-mail: kassatad@yahoo.com
}

\begin{abstract}
Nowadays climate change is expected to affect society in a number of ways ranging from food security to water resources. Water plays an important role in the socio-economic development of any society. Thus, this study mainly deals with assessing climate change impact on water availability of Bilate watershed, Ethiopian Rift Valley Basin. The watershed is situated in Ethiopian Rift Valley Basin and covers an area of about $3643 \mathrm{~km}^{2}$ in which Bilate river is the main river flowing throughout the year.To project the probable impact of climate change on the available water, HadCM3 coupled atmosphere-ocean GCM model was used since it is the only GCM model that has grid box containing the study area for SDSM. The output of HadCM3 coupled atmosphereocean GCM model for the A2a and B2a SRES emission scenarios were used to produce future scenarios of precipitation and temperature. Climate change scenarios of precipitation and temperature were developed at two upper and lower stations of the watershed for three periods namely; 2020s (2011-2040), 2050s (2041-2070) and 2080s (2070-2099 and their respective changes were determined as deltas (for temperature) and as percentages (for precipitation) from the base period values. The future climate variable such as daily precipitation, maximum and minimum temperature found as an output from the GCM model and downscaled by the SDSM model and likely change in land use were given directly as an input to the SWAT model. The SWAT simulation of future average annual flow shows a decreasing trend in 2011-2040 periods and an increasing trend in 2041-2070 periods. The average total annual flow at outlet of the watershed might decrease up to $3.7 \%$ for A2a scenario and $1.5 \%$ for B2a scenario for the 2011-2040 periods but for 2041-2070 periods it might increase up to $2.6 \%$ for A2a scenario and 3.7\% for B2a scenario. The decrease in the future flow of 2011-2040 periods might be insufficient in some months to meet future demands for water of the ever increasing population with in and around the watershed. Adopting water storage options to store the excess water flowing during the rainy period is crucial.
\end{abstract}

Keywords: A2a, B2a, Bilate, Climate Change, Ethiopia, GCM, HadCM3, Rift Valley, Scenario, SDSM, SRES, SWAT, Water storage

\section{Introduction}

Climate change is associated with global warming that is induced by the increase in carbon dioxide and other radioactive trace gases in the atmosphere. This was the focus of scientific investigations due to the fact that climate change has significant implications for the environment, ecosystems, water resources and virtually every aspect of human life (IPCC, 2001).

The most important and immediate effects of global warming would be the changes in local and regional water availability, since the climate system is interactive with hydrologic cycle (ARORA and BOER, 1996)

Ethiopia is vulnerable to climate change since the economy of the country mainly depends on agriculture, which is very sensitive to climate change and variations. In Bilate watershed the increase in population growth, economic development together with climate change is expected to cause an increase of water demand for different purposes.

Due to climate change, water and its availability and quality will be the main pressures on, and issues for, societies and the environment. Climate change also increase the vulnerability of ecosystems due to temperature increases, changes in precipitation patterns, frequent severe weather events such as flooding and prolonged droughts (IPCC, 2007).

Owing to rapid growth in population, the need for the optimum development of water resources has become more urgent than ever. Population distribution, irrigated agriculture, urban and industrial water use are major factors deriving water availability issues. The impact of climate change on water availability of Bilate watershed is not well investigated in terms of both quantity and quality.

The study was conducted to assess impacts of climate change on water availability of the watershed by 
developing temporal climate change scenarios (precipitation and temperature) for the future periods of 20112099 and to quantify the possible impacts of the climate change on the available water for the period of 2011 till 2070 using SWAT model.

\section{Study area and Data availability}

The study area is situated in the southwestern part of Ethiopia and it is one of the major watersheds in the Ethiopian Rift Valley Basins which is named as Bilate watershed. It is located roughly between $37^{\circ} 47^{\prime} 6^{\prime \prime}$, to $38^{0} 20^{\prime} 14^{\prime \prime}$ E and $6^{0} 33^{\prime} 18^{\prime \prime}$ to $8^{0} 6^{\prime} 57^{\prime}$ 'N latitudes and longitudes respectively. The watershed covers a drainage area of about $3643 \mathrm{~km}^{2}$.

The watershed is usually classified in to three sub-basins: the upper, the middle and the lower subbasins with total annual rainfall of 1280-1339, 1061-1516, and 769-956mm respectively.

Generally, in the highlands of Bilate watershed like Hossana, the mean annual temperature varies from $11^{\circ} \mathrm{c}$ in August to $22^{\circ} \mathrm{c}$ in March/April while the temperature variation in the lower part of Bilate (Bilate farm) generally is higher and ranges between $16^{\circ} \mathrm{c}$ in July to $30^{\circ} \mathrm{c}$ in January and March. The elevation of Bilate watershed ranges between 3347 meter a.m.s.l in the north and 1408 meter in the south with a mean elevation of 2013.4 meters.

Meteorological data was collected from the Ethiopian National Meteorology Agency as they are required for downscaling the GCM data using Statistical Downscaling Model (SDSM) and as an input to the Soil and Water Assessment Tool (SWAT) model. Stream flow data were also collected from Ethiopian Ministry of Water Resources (MoWR) for calibrating and validating SWAT model. The climate scenario data used for Statistical Downscaling Model was obtained from the Canadian Institute for climate studies website for model output of HadCM3.

\section{Methodological Approach}

The general methodology consists of using climatic output data from general Circulation models (GCMs) to retrieve climate scenarios. The weather generator was then used to produce daily temperature and precipitation data to serve as an input data for the SWAT hydrological model to simulate stream flow. The future simulated results were then compared with the base line period as a means of obtaining the change caused by climate change. The detail methodology of the study is clearly stated below.

\section{Statistical Downscaling Model (SDSM) Climate change scenario}

The climate change scenarios produced for this study were based on the outputs of GCM results that are established on the SRES emission scenarios. The outputs of HadCM3 GCM model for the A2 and B2 emission scenarios were used to produce the future scenarios. The SDSM was adopted to downscale the global scale outputs of the HadCM3 model outputs into the local watershed scale. As described by (PLAMER et al, 2004), this method is advantageous as it is easy to implement, and generation of the downscaled values involves observed historic daily data. The latter advantage ensures the maintenance of local spatial and temporal variability in generating realistic time series data.

The future time scales from the year 2011 until 2099 were divided into three periods of 30 years and their respective changes were determined as deltas (for temperature) and as percentages (for precipitation) from the base period values.

\section{HadCM3: Coupled Atmosphere-Ocean GCM model}

The HadCM3 model was selected for the impact study due to the availability of a downscaling model called SDSM that is used to downscale the result of HadCM3 and CGCM1 models. Consequently, all the data files used in this study were only for the HadCM3 GCM. The model results are available for the A2 and B2 scenarios, where A2 is referred to as the medium high emissions scenario and B2 as the medium low emissions scenario. For two of these emission scenarios three ensemble members ( $a, b$, and $c$ ) are available, where each refer to a different initial point of climate perturbation along the control run (HANSON, 2004). During this study data were available only for the "a" ensembles and hence only the A2a and B2a scenarios were considered.

\section{SDSM Model approach}

As Bilate Farm and Hossana stations have long continuous records and are well distributed in the watershed these two stations are used for downscaling global climate change to local impact assessment. Hence, future climate variables such as precipitation, maximum and minimum temperature of those two stations were compared with the base period. The key functions of SDSM such as Quality Control and Data Transformation, Screening of Downscaling Predictor Variables, Model Calibration, Weather Generator and Validation and Scenario Generation has been done based on universal settings used in the model provided by WILBY and 
DAWSON, 2007. The base period used for the model was from 1/1/1972 to 31/12/2001 for both stations. Based on the selected predictor variables model calibration was done for 15 years from 1979-1993 for Bilate Farm and 20 years from 1972-1991 for Hossana stations at a monthly model type in order to see the monthly temporal variations. The result of the weather generator was used to validate the calibrated model using independent observed data not used during the calibration procedure and the synthesized artificial weather time series data representing the present condition. Eight years of simulation from 1994-2001 was used for validation at Bilate farm station and ten years 1992-2001 was used for Hossana station. HadCM3A2a and HadCM3B2a were the two GCM output files used for the scenario generation and the regression weights produced during the calibration process were applied to the time series outputs of the GCM model. Twenty ensembles of synthetic daily time series data were produced for each of the two SRES scenarios for a period of 139 years (1961 to 2099). The final product of the SDSM downscaling method was then found by averaging the twenty independent stochastic GCM ensembles and comparison was done between observed and downscaled base line future data's. Baseline scenarios, which reflect current conditions, were initially executed prior to performing the scenario simulations. Accordingly 30-year period from1972-2001 was selected for both Bilate Farm and Hossana stations to represent baseline. The future scenarios were developed by dividing the future time series in to three equal periods of 30 years: 2011-2040, 2041-2070, 2071-2099.

\section{Soil and Water Assessment Tool (SWAT) hydrological model}

For this study SWAT hydrological model was selected for the impact assessment as the model is physically based, spatially distributed, and it belongs to the public domain and (LENAHART et al, 2002), and computationally efficient hydrological model, which uses readily available inputs.

Watersheds were subdivided into sub watersheds and further into hydrologic response units (HRUs) to account for differences in soils, land use, crops, topography, weather, etc. The model has a weather generator sub routine that generates daily values of precipitation, air temperature, solar radiation, wind speed, and relative humidity from statistical parameters derived from average monthly values. SWAT has three options for estimating potential evapotranspiration: Hargreaves, Priestley-Taylor, and Penman-Monteith in which Hargreaves method was selected at it requires air temperature only. SWAT splits hydrological simulations of a watershed into two major phases: the land phase and the routing phase. The difference between the two lies on the fact that water storage and its influence on flow rates is considered in channelized flow (NEITSCH et al, 2002). Two weather generator stations such as Bilate Farm and Hossana were selected to generate missing weather data in SWAT simulation model. For data generation, weather parameters were developed using the weather parameter calculator WXPARM (WILLIAMS, 1991) and Dew point temperature calculator DEW02 (LIERSCH, 2003).

\section{Sensitivity analysis, Calibration and Validation}

The sensitivity analysis in this study was undertaken by using a built-in tool in SWAT that uses the Latin Hypercube One-factor-At-a-Time (LH-OAT) design method of Morris (1991). After the analysis, the mean relative sensitivity (MRS) of the parameters was used to rank the parameters and their category of sensitivity was also defined based on the (LENAHART et al, 2002), classification such as very high, high, medium and small. (DELNESAW, 2006), indicated that there can be a significant variation of hydrological processes between individual watersheds. This, therefore, justified the need for the sensitivity analysis made for each of the two sub watersheds in the study area. The analysis involved a total of 26 parameters.

Model simulations were evaluated by using mean, standard deviation, regression coefficient $\left(\mathrm{R}^{2}\right)$, and the Nash and Suttcliffe simulation efficiency $\left(\mathrm{E}_{\mathrm{NS}}\right)$ (Nash and Suttcliffe 1970).

A combination of both manual and automatic calibration method was used for the model simulation. First manual calibration has been used mainly for annual water balance and it was followed by automatic calibration. The calibration was done using historical records of five years. However, the simulation was run for six years, where the first year was used to "warm-up" the model. In the validation process, data for a period of three years was used to evaluate the model accuracy. The statistical criteria used during the calibration procedure were also checked here to make sure that the simulated volume is still within the accuracy limits.

\section{SWAT Model Setup}

The model setup involved five steps: (1) data preparation, (2) sub basin discretization, (3) HRU definition, (4) parameter sensitivity analysis, (5) calibration and uncertainty analysis. The required spatial data sets were projected to the same projection called WGS 1984_UTM Zone $37 \mathrm{~N}$, which is the transverse Mercator projection parameters for Ethiopia, using Arc GIS 9.2. The Land use/Land cover spatial data were reclassified into SWAT land cover/plant types. The SWAT codes for the different categories of land cover/land use were feed manually on the map as per the required format. The soil map was linked with the soil data-base which is a soil database designed to hold data for soils not included in the U.S. The watershed delineation process includes five major 
steps such as DEM setup, stream definition, outlet and inlet definition, watershed outlets selection and definition and calculation of sub basin parameters. For the stream definition the threshold based stream definition option was used to define the minimum size of the sub basin. The Arc SWAT interface allows the user to fix the number of sub basins by deciding the initial threshold area. The spatially distributed data (GIS input) needed for the Arc SWAT interface include the Digital Elevation Model (DEM), soil data, and land use data. Data on weather and flow is used for prediction of water balance and calibration purposes respectively.

\section{Determination of Impacted Future Flow rate}

SWAT was applied to simulate the impacts of climate change on river flow by assuming that change in precipitation, temperature and land use in the future from base line period affects flow volume. The future climate variable such as daily precipitation, maximum and minimum temperature found as an output from the GCM model and downscaled by the SDSM model and assumed change in land use were given directly as an input to the SWAT model. Other climate variables such as wind speed, solar radiation, and relative humidity were assumed to be constant throughout the future simulation periods. The future two periods, 2011-2040 and 2041-2070 of both Bilate Farm and Hossana station data's obtained from SDSM output and change in land use were used as an input in SWAT model to determine the impact of climate change on future stream flow volume. The SWAT simulation for the 1991 to 2010 period was used as a baseline period against which the climate impact was assessed. The SWAT model was then re-run for the future periods with the downscaled output of climate variables and assumed land use changes to compare them with the baseline period model results.

\section{Results and Discussions}

\section{Climate change model results}

\section{Scenarios developed for base period}

Even though the SDSM model performs reasonably well in estimating the mean monthly precipitation at Bilate farm in many months but in some months especially in rainy seasons such as April, May, and July there is a relatively large model errors. But at Hossana station SDSM doesn't able to simulate except for some months such as January, February and October. This is to mean that, the model underestimates in months of April to September. But the model overestimates in months of March, November and December. The result, however, can be taken as satisfactory in such a way that precipitation downscaling is necessarily more problematic because of daily precipitation amounts at individual sites are relatively poorly resolved by regional scale predictors than temperature.
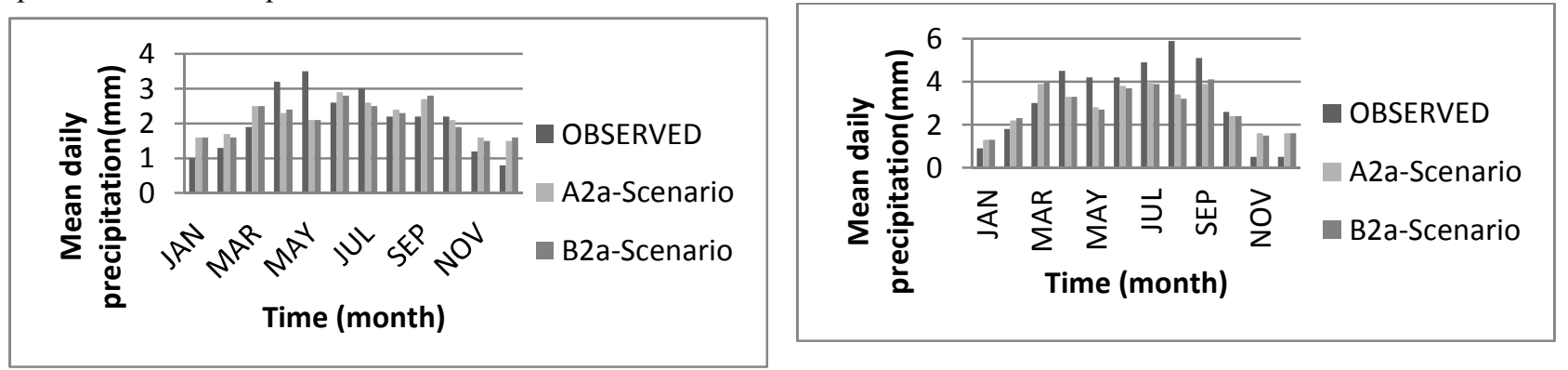

Fig1: Average daily precipitation at Bilate Farm and Hossana station for the base period (1972-2001).

With respect to monthly maximum temperature at both stations, the SDSM model slightly underestimates for some months such as January, February and March but in some months like July, August and September there is overestimation of the model. In other months the downscaled maximum temperature shows good agreement with observed values. 

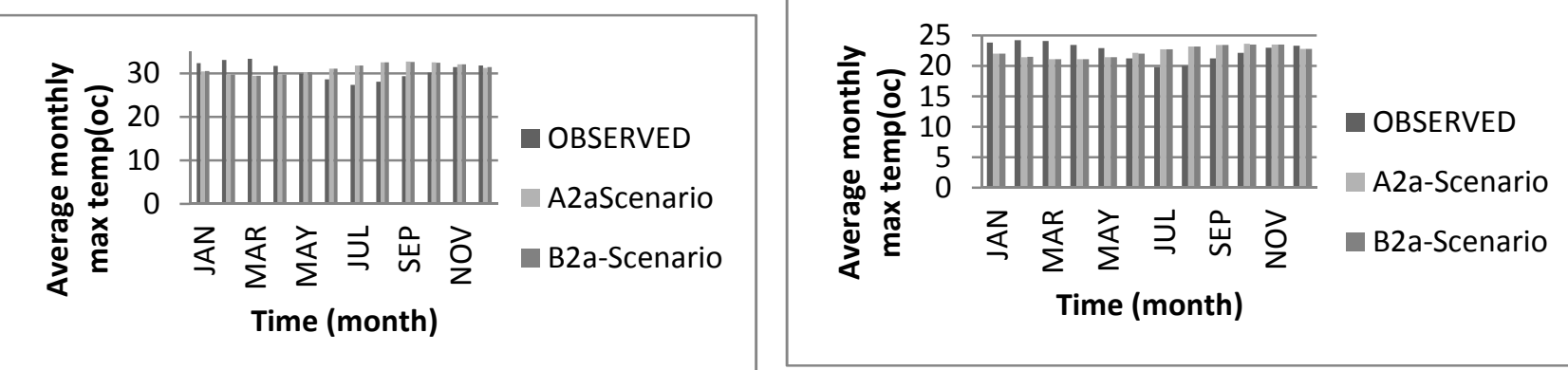

Fig2: Average monthly maximum temperature at Bilate Farm and Hossana station for the base period (19722001).

Regarding the minimum temperature at both stations except for month of October and December, the model slightly underestimates for all other months but in a month of November there is overestimation of the model. In general, the generated minimum temperature follows the same trend with that of observed ones.
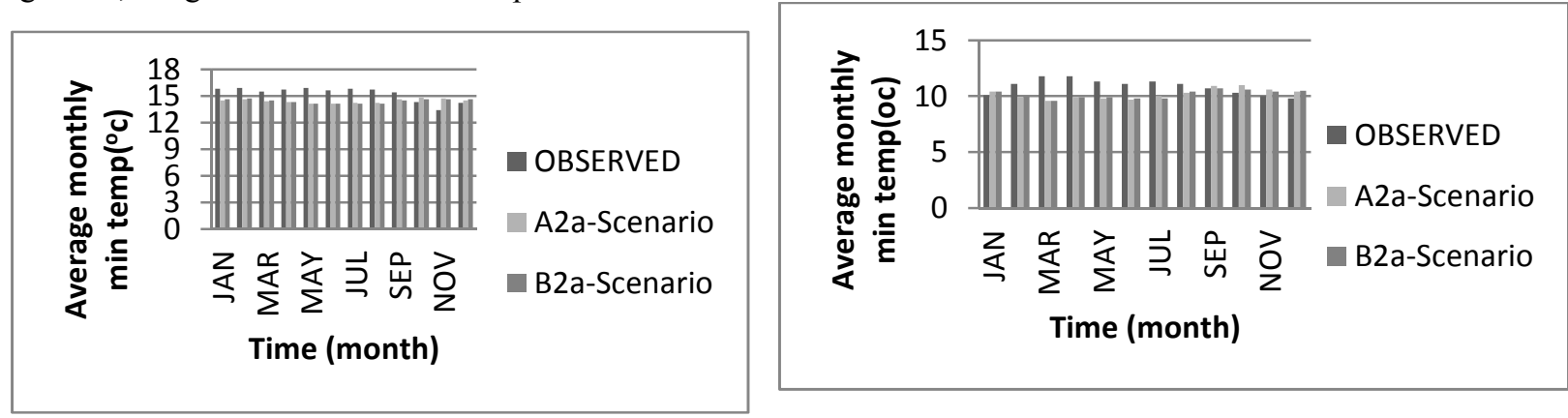

Fig3: Average monthly minimum temperature at Bilate Farm and Hossana station for the base period (19722001).

Scenarios developed for the future period

As A2a and B2a scenarios generated values are not significantly different we will try to see the future change of either A2a or B2a scenario for all the climatic variables.

Based on the precipitation scenario generated at Bilate farm station, generally the average monthly precipitation shows an increasing trend from the base period. But in the months of March and September the average monthly precipitation shows a decrease from the base period. The increase in average monthly precipitation might be higher especially during August, November and December. In the case of Hossana station, generally the average monthly precipitation shows a decreasing trend from the base period. However, in months of November and December there might be an increase of monthly precipitation.
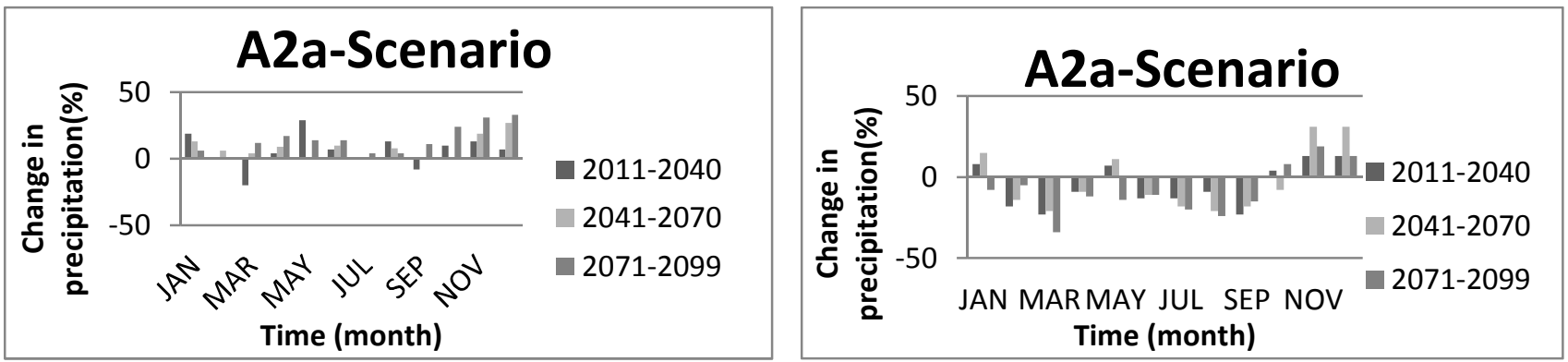

Fig4: Percentage change in average monthly precipitation in the future from the base period at Bilate Farm and Hossana stations.

For Bilate Farm station, the downscaled maximum temperature scenario indicates that there might be an increasing trend from January to June for from the base period. But from July to December the projected maximum temperature shows a decreasing trend for both scenarios. In case of Hosanna station, the downscaled maximum temperature scenario indicates that there will be generally an increasing trend from January to June especially for the periods of 2011-2040 and 2071-2099. But for the period of 2041-2070 there is a decreasing 
trend. Based on monthly basis, from July to December the projected maximum temperature shows a decreasing trend.
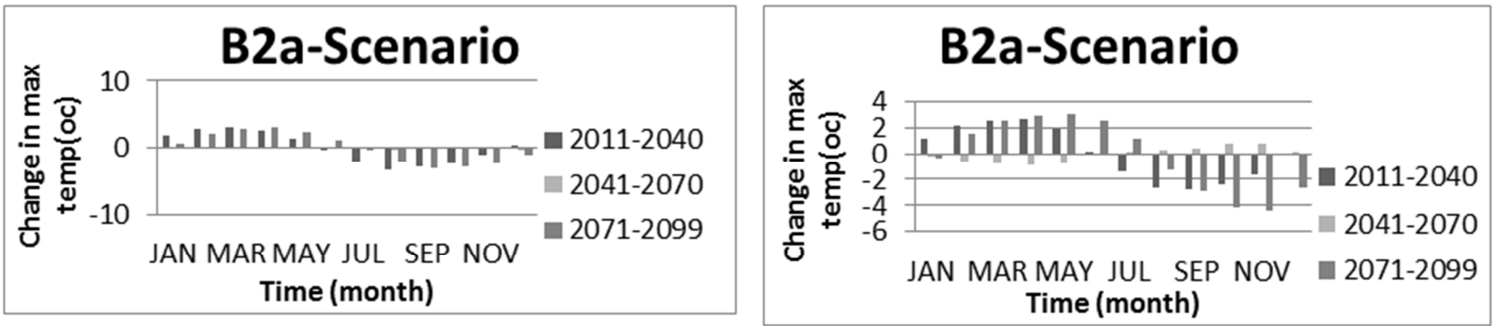

Fig5: Change in average monthly maximum temperature in the future from the base period at Bilate Farm and Hossana stations.

For Bilate Farm station, like precipitation and maximum temperature scenario generated, the average monthly minimum temperature also indicates that there is an increasing trend from the base period. But there is a slight decrease in October and November. For Hosanna station, the change in average monthly minimum temperature will be between $-5.0^{\circ} \mathrm{c}$ in October (2070-2099 period) and $+5.4^{\circ} \mathrm{c}$ in June (2070-2099 period).
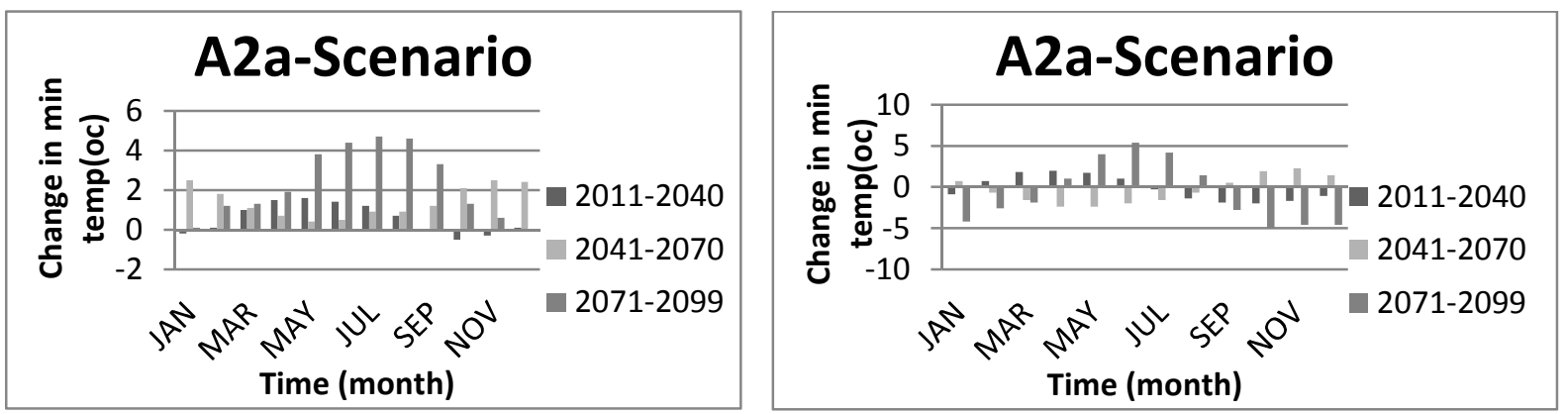

Fig6: Change in average monthly minimum temperature in the future from the base period at Bilate farm and Hossana stations.

SWAT Hydrological Model Results

Flow Calibration and validation

The calibration results show that there is a good agreement between the simulated and gauged monthly flows at the out let of the watershed i.e. at Bilate Tena gauging station. This is demonstrated by the correlation coefficient $\left(\mathrm{R}^{2}=0.79\right.$ and $\mathrm{R}^{2}=0.76$ during calibration and validation period), the Nash-Suttcliffe (1970) simulation efficiency $\left(\mathrm{E}_{\mathrm{NS}}=0.77\right.$ and $\mathrm{E}_{\mathrm{NS}}=0.75$ during calibration and validation period) and percent deviation $(\mathrm{D}=1.83$ and $\mathrm{D}=-2.48$ during calibration and validation period). The results fulfilled the requirements suggested by (Santhi et al, 2001) for $\mathrm{R}^{2}>0.6$ and $\mathrm{E}_{\mathrm{NS}}>0.5$.
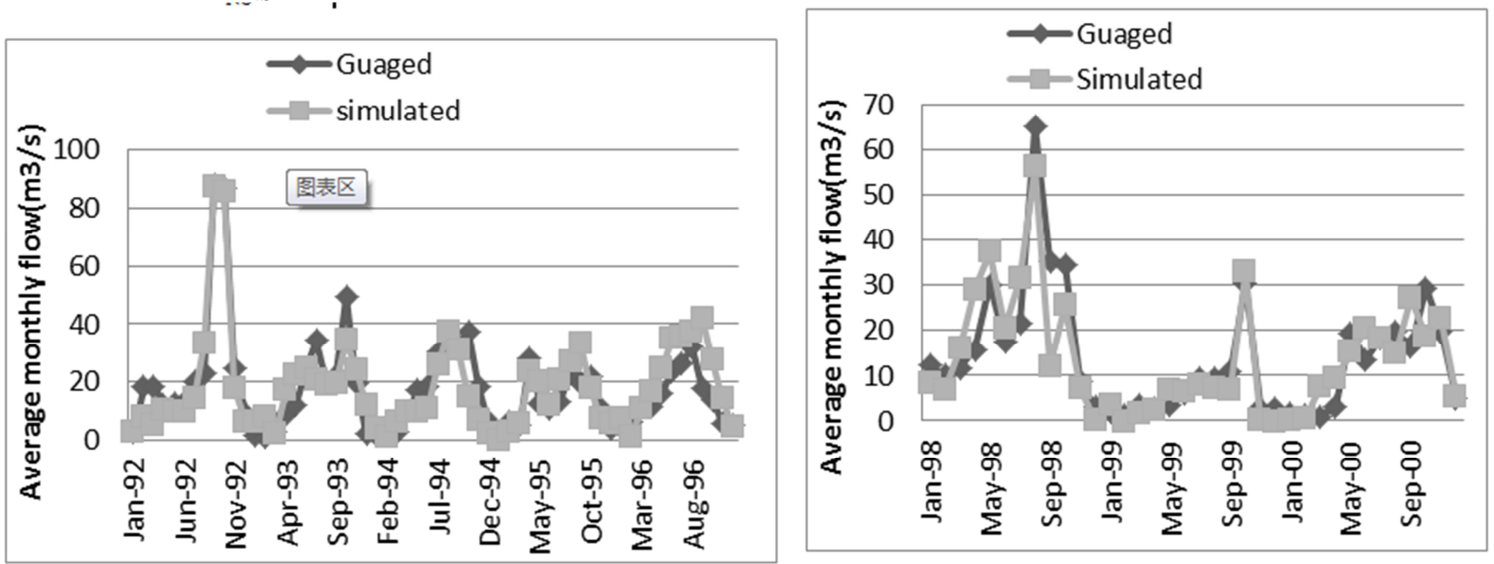

Fig7: Calibration and validation result of average monthly simulated and gauged flows at the outlet of Bilate watershed. 


\section{Annual Water Balance}

Average annual water balance for both calibration and validation period result from simulation showed that the largest portion of the average annual precipitation (76.26\%) falling in the watershed is lost through evaporation. This value indicates that there is high sensitivity of evapotranspiration to any change than any other hydrologic parameter governing the sub watersheds' water balance.

Table1: Average annual water balance for both Calibration and Validation periods.

\begin{tabular}{|c|c|c|c|c|}
\hline \multirow[b]{2}{*}{$\begin{array}{l}\text { Hydrological } \\
\text { parameter }\end{array}$} & \multicolumn{2}{|c|}{ Simulated values(mm) } & \multirow[b]{2}{*}{$\begin{array}{l}\text { Weighted } \\
\text { average }\end{array}$} & \multirow[b]{2}{*}{$\begin{array}{l}\% \text { of yearly } \\
\text { precipitation }\end{array}$} \\
\hline & $\begin{array}{c}\text { calibration } \\
\text { period(1992-1996) }\end{array}$ & $\begin{array}{c}\text { Validation } \\
\text { period(1998-2000) }\end{array}$ & & \\
\hline Precipitation & 1151.30 & 1178.60 & 1161.54 & \\
\hline Surface runoff & 62.77 & 81.21 & 69.69 & 6.00 \\
\hline Base flow & 45.92 & 45.96 & 45.94 & 3.95 \\
\hline Revap/Shallow AQ & & & & \\
\hline recharges & 120.82 & 115.41 & 118.79 & 10.23 \\
\hline Deep AQ recharges & 7.10 & 6.71 & 6.95 & 0.60 \\
\hline Total AQ recharge & 142.03 & 134.12 & 139.06 & 11.97 \\
\hline Total water yield & 107.66 & 125.19 & 114.23 & 9.83 \\
\hline $\begin{array}{l}\text { percolation out of soil } \\
\text { Actual }\end{array}$ & 141.44 & 134.50 & 138.84 & 11.95 \\
\hline Evapotranspiration & 887.00 & 883.70 & 885.76 & 76.26 \\
\hline Transmission losses & 1.02 & 0.98 & 1.01 & 0.09 \\
\hline
\end{tabular}

Climate Change Impact on Future Flow

Impact on Future Monthly Flow
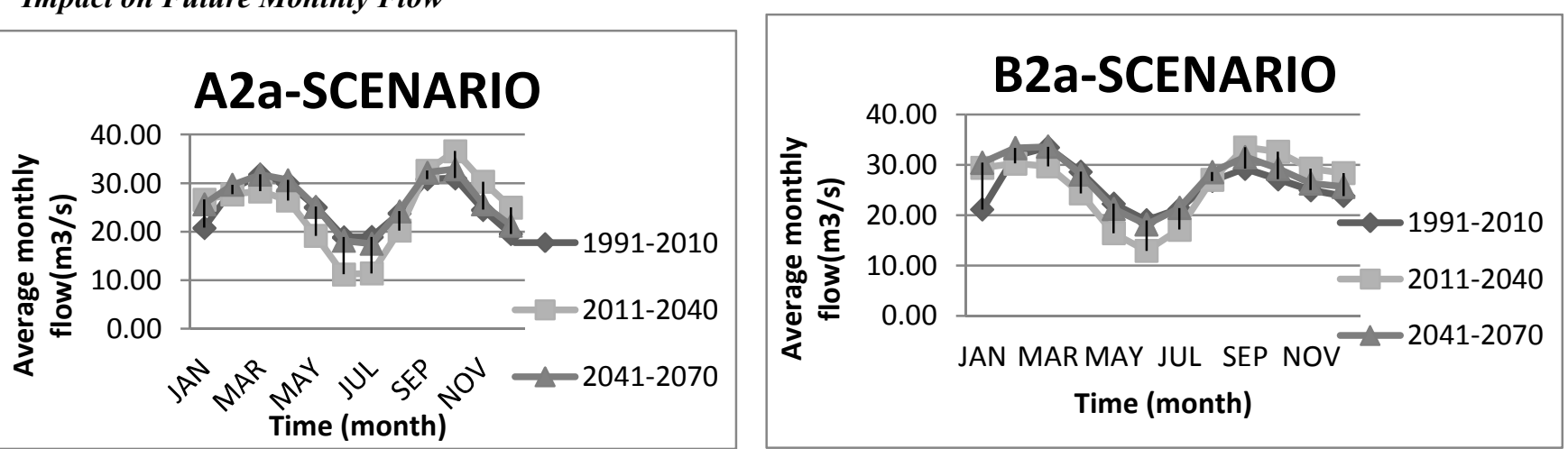

Fig8: Average monthly flow pattern at the out let of the watershed.

In both A2a and B2a scenarios there is a slight increase of average monthly flow in months of September, October, November, December and January. On the other hand, there is a slight decrease of average monthly flow in other months. Generally, the decreasing and increasing pattern seems to be higher in the time period of 2011-2040. In general there is a decrease of base flow during dry months but during the rainy months there is an increase of peak surface flow.

Impact on Future Seasonal and Annual Flow

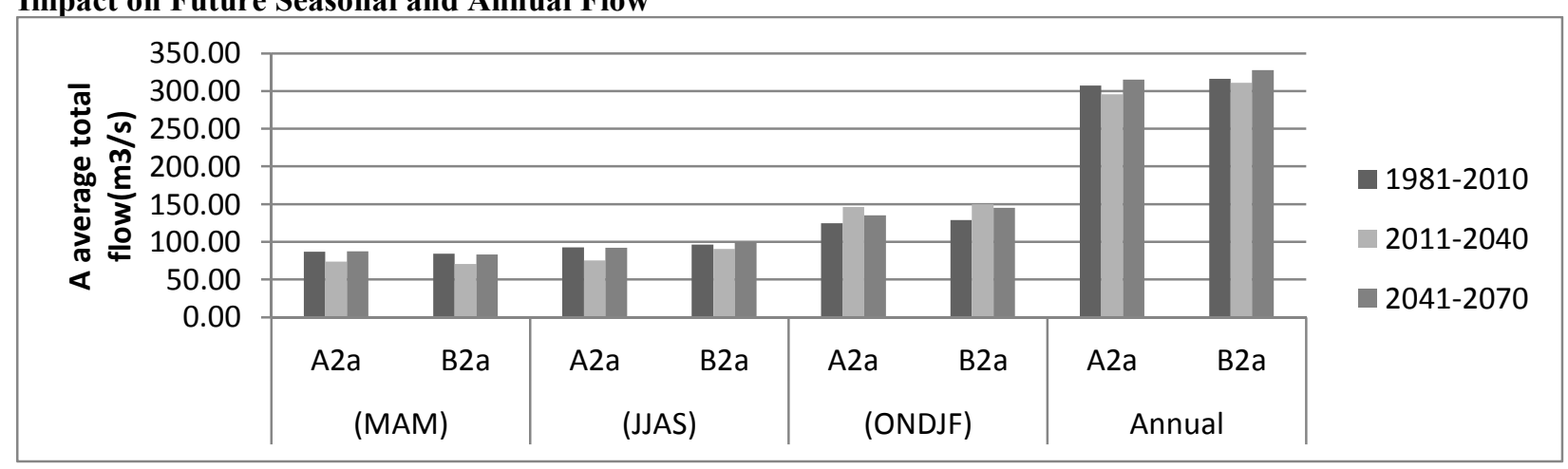

Fig9: Average total seasonal and annual flow pattern at the out let of the watershed. 


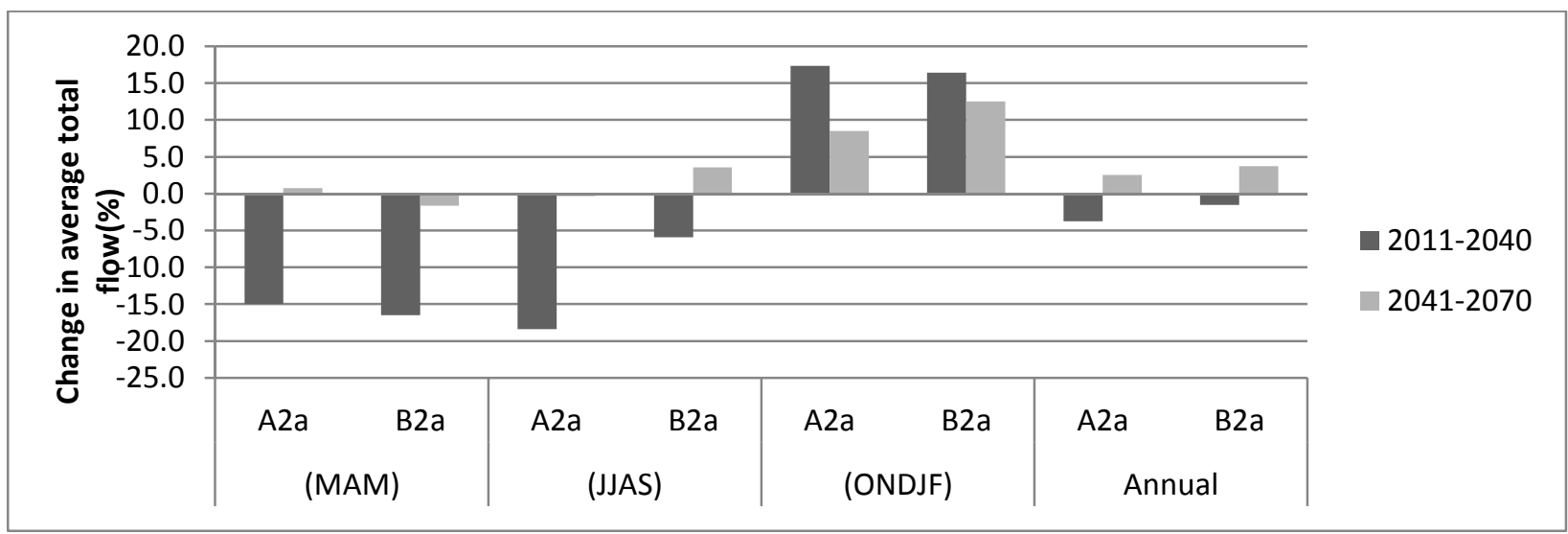

Fig10: Percentage change of average total seasonal and annual flow pattern at the out let of the watershedin In general the average total seasonal flow shows decreasing pattern in month of March to September for A2a scenario but for B2a scenario it is almost constant. But in months of October to February there might be an increasing pattern of average total seasonal flow in both scenarios. In 2011-2040 period, the average total annual flow might decrease by 3.7\% and 1.5\% for A2a and B2a scenarios respectively. But in 2041-2070 period, it might increase by $2.6 \%$ and $3.7 \%$ for $\mathrm{A} 2 \mathrm{a}$ and $\mathrm{B} 2 \mathrm{a}$ scenarios respectively. This decrease of average total annual flow in both scenarios in 2011-2040 period might be due to the fact that decrease of a total average annual precipitation in Hossana station is higher than the increase of precipitation in Bilate farm station and slight increase of annual minimum temperature in both scenarios of Bilate station in SDSM out puts results.

\section{Climate change adaptation strategies}

In general adaptation to climate change problems causing reduction in the total water yield can be the range of actions taken in response to changes in local and regional climatic conditions. These responses include autonomous adaptation, i.e., actions taken by individual actors such as single farmers or agricultural organizations, as well as planned adaptation, i.e., climate-specific infrastructure development, regulations and incentives put in place by regional, national and international policies in order to complement, enhance and/or facilitate responses by farmers and organizations. For the 2011-2040 periods, watershed based integrated water resource management approach is the possible adaptation options to be implemented to overcome the reduction of average monthly flow in some months of the watershed.

\section{Conclusions and Recommendations}

The SDSM has good ability to replicate the historical maximum and minimum temperatures than precipitation. A SWAT hydrological model simulation has shown that the model is able to simulate the observed stream flow in the watershed reasonably. This is proved during calibration and validation period of the model performance criterion such as regression coefficient and Nash-Sutcliffe used to evaluate the model.

The change in climate variables such as decrease in precipitation and increase in temperature thereby increase in evapotranspiration which is very sensitive parameter that can be affected by changing climate than any other hydrological component are likely to have significant impact on Stream flow. There is an increase of water demand due to an increase of human need of water for different purposes. This in combination of the future climate change impact on reduction of the available water in the watershed causes a water stress within and around the watershed.

\section{References}

1. ARORA and BOER. (1996). The effect of simulated climate change on the hydrology of major river basins. Water resource Res.Submitted.

2. DELNESAW. (2006). Modelling of Hydrology and Soil erosion of upper Awash River basin, PhD Thesis, University of Bonn. 233pp.

3. HANSON. (2004). Emmision scenario dependencies in climate change assessment of the hydrologic cycle. Earth and Environmental Sceince, vol.99, No.1-2, 321-329pp.

4. IPCC. (2001). The Scientific Basis, Technical Summary of the Working group I. [Housghton,J.t.,Y. Ding.D.J. Griggs,M.Noguer, P.J. Vander Linden, X. Dani K. Maskell, and C.A. Jhonsouleds]. Combridge University press, Combridge, United Kingdom and New yourk,NY, USA, 94pp.

5. IPCC, AR4. ( 2007). Climate Change 2007, Synthesis report. Summary for Policymakers. Valentia, Spain

6. LENAHART et al. (2002). Comparison of two different approaches of sensitivity analysis, Physics and Chemistry of the earth 27. Elsevier science LTD , 645-654pp. 
7. LIERSCH. ( 2003). Dew02 users' Mannual. 5pp.

8. NEITSCH et al. (2002). Theoretical Documentation, version 2002. Grass land Soil and Water Research Laboratory, Black land research center, Texas Agricultural Experiment station, Texas Water Resource Institute, College Station, 506pp.

9. SANTHI et al. (2001). Validation of the SWAT Model on a Large River Basin with point and Non point sources. Journal of the American Water Resource Association, Vol 37,1169-1188pp.

10. PLAMER et al. (2004). Impact of climate change on the Tualatin River Basin water supply. An investigation in to the projected hydrologic and management impacts. Department of Civil and Environmenteal Engineering, University of Washington.

11. WILBY and DAWSON. (2007). Using SDSM Version 4.2 A Decision Support tool for the Assessment of regional Climate Change Impacts Users Mannual. UK.

12. WILLIAMS. (1991). Weather parameter generating utility. USDA/ARS Grassland Soil and Water Research Laboratory, Temple. 
The IISTE is a pioneer in the Open-Access hosting service and academic event management. The aim of the firm is Accelerating Global Knowledge Sharing.

More information about the firm can be found on the homepage:

http://www.iiste.org

\section{CALL FOR JOURNAL PAPERS}

There are more than 30 peer-reviewed academic journals hosted under the hosting platform.

Prospective authors of journals can find the submission instruction on the following page: http://www.iiste.org/journals/ All the journals articles are available online to the readers all over the world without financial, legal, or technical barriers other than those inseparable from gaining access to the internet itself. Paper version of the journals is also available upon request of readers and authors.

\section{MORE RESOURCES}

Book publication information: http://www.iiste.org/book/

\section{IISTE Knowledge Sharing Partners}

EBSCO, Index Copernicus, Ulrich's Periodicals Directory, JournalTOCS, PKP Open Archives Harvester, Bielefeld Academic Search Engine, Elektronische Zeitschriftenbibliothek EZB, Open J-Gate, OCLC WorldCat, Universe Digtial Library, NewJour, Google Scholar

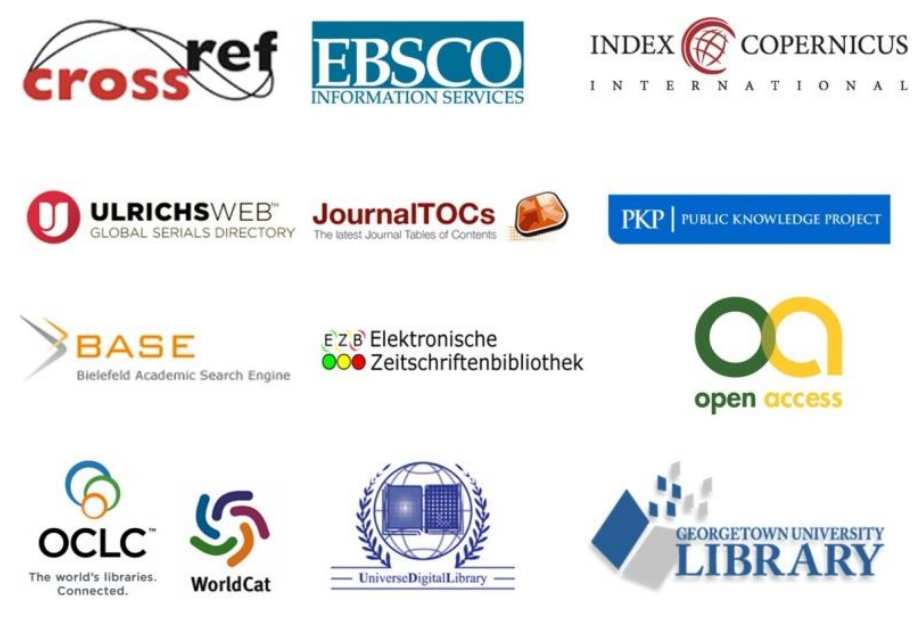

